\title{
MERANCANG SIMULASI JARINGAN MENGGUNAKAN CISCO PACKET TRACER BERBASIS ANDROID
}

\author{
Muhamad Juliardi, Harry Dhika \\ Jurusan informatika,Fakultas Teknik dan Ilmu komputer \\ Universitas Indraprasta PGRI \\ Jl.Nangka No. 58C Tanjung Barat, Jagakarsa-Jakarta Selatan \\ dhikatr@yahoo.com
}

\begin{abstract}
Abstrak. Dalam sejarah, perkembangan komputer selalu mengalami peningkatan dan perkembangan, dengan bertambahnya kemajuan jaman, kita di tuntut untuk mengikutinya sekreatif mungkin, sehingga persaingan dalam dunia teknologi semakin meningkat, demi memenuhi koneksi jaringan internet, ada banyak cara yang bisa kita tempuh, salah satunya adalah menggunakan Cisco packet tracer, cisco packet tracer adalah sebuah media aplikasi untuk mempermudah dalam menghubungkan setiap komputer, dengan beberapa ikon yang bisa kita manfaatkan di dalam aplikasi tersebut, kita mampu membuat simulasi jaringan hanya dengan menggunakan aplikasi ini, namun dengan perkembangan jaman yang begitu pesat, aplikasi ini telah ada di dalam platform Android, sehingga memudahkan kita untuk menggunakan aplikasi ini hanya dengan via telpon genggam, aplikasi android ini bernama packet tracer mobile, aplikasi ini merupakan sebuah cross-platform visual alat simulasi jaringan yang inovatif dan kuat yang digunakan untuk latihan, penemuan, dan pemecahan masalah yang dirancang oleh Cisco systems yang memungkinkan pengguna untuk memvisualisasikan proses internal secara real-time, seperti transfer data dinamis dan expansi konten paket yang biasanya di sembunyikan di perangkat nyata .Perangkat lunak ini mendesain, membangun, konfigurasikan dengan perangkat seret lepas. Hasil dari penelitian ini sangat bermanfaat bagi seorang administrator jaringan dalam memberi gambaran seputar jaringan yang akan nantinya akan dibuat.
\end{abstract}

Kata kunci-simulasi, jaringan komputer, cisco paket tracer.

\section{PENDAhUluAN}

Semakin berkembangnya teknologi informasi pada saat ini, maka kebutuhan akan informasi sangatlah dibutuhkan dalam hal ini kebutuhan akan sebuah jaringan komputer. Dalam sebuah perusahaan jaringan komputer sangat berperan penting dalam menunjang aktivitas pekerjaan para karyawan, untuk itu dibutuhkan sebuah jaringan yang memiliki arsitektur canggih dan juga modern, akan tetapi fakta dilapangan banyak ditemukan permasalahn dalam jaringan itu sendiri, misalnya jaringan tersebut mengalami offline, lemot dan lain sebagainya.

Mengingat kebutuhan jaringan komputer yang begitu penting tentunya informasi seputar jaringan komputer yang sedang digunakan menjadi kebutuhan bagi seorang administrator jaringan dalam mengawasi hal tersebut sehingga membutuhkan sebuah aplikasi mengenai simulasi jaringan yang murah dan cepat. (Ramadhan and
Mubarakah 2013). Dengan menggunakan packet tracer mobile, simulasi mengenai jaringan komputer dapat dimanfaatkan oleh seorang admin jaringan menjadi sebuah informasi yang berguna untuk seorang administrator dalam network monitoring system tentang keadaan koneksi dalam suatu jaringan, apabila terjadi masalah/eror dalam suatu interkoneksi jaringan komputer maka akan mudah dalam mengetahui jaringan komputer yang mengalami troubleshooting (Mufadhol 2012). Aplikasi ini sangat membantu dalam hal memberikan gambaran kepada seorang administrator sebelum membuat jaringan yang sesungguhnya sehingga dapat meminimalisir kesalahan yang terjadi.

\section{METODE}

Dalam kegiatan menulis penulis melakukan praktek dengan beberapa hal :

1. Menggunakan cisco packet tracer mobile untuk membuat simulasi jaringan. 
2. Membuat dua buah jaringan komputer dengan menggunakan topologi star.

3. Mengkoneksikan antar kedua jaringan tersebut dengan menggunakan router.

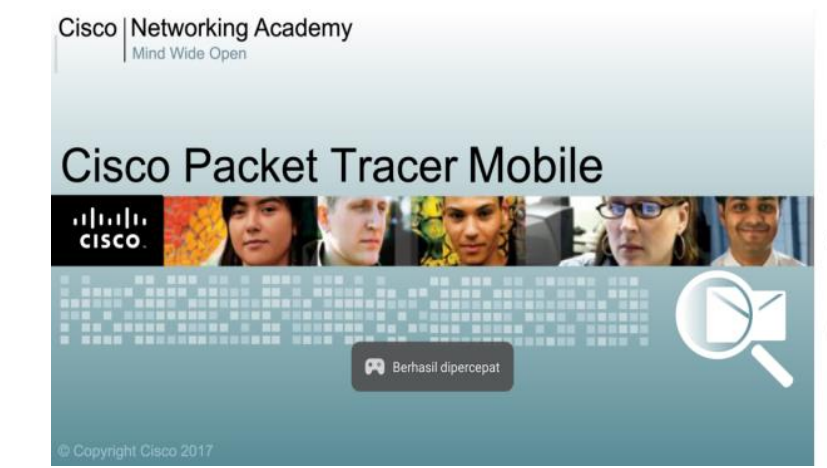

Gambar 1. Aplikasi Cisco Packet Tracer mobile

\section{LANDASAN TEORI}

Jaringan komputer adalah sebuah system yang terdiri dari beberapa komputer atau lebih yang saling terkoneksi melalui sebuah media transmisi atau sebuah media telekomunikasi sehingga dapat saling berbagi berbagai data, berbagi aplikasi maupun berbagi perangkat komputer.Jaringan komputer merupakan penggabungan antara dua teknologi yaitu teknologi telekomunikasi dan juga teknologi komputer, dimana dari penggabungan dua teknologi tersebut menghasilkan sebuah teknologi data yang mana bisa diaplikasikan sebuah komputer.Tiap komputer atau peripheral yang terhubung dengan jaringan disebut dengan node. Sebuah jaringan komputer dapat memiliki puluhan, ribuan, bahkaan jutaan node.

\subsection{Menentukan Bentuk Jaringankomputer}

Untuk menentukan sebuah topologi jaringan maka sesuaikan bentuk jaringan tersebut sesuai dengan bentuk jaringan yang dibutuhkan, dalam simulasijaringan ini menggunakan topologi star karena topologi ini mudah dan sederhana serta banyak juga digunakan oleh sebuah perusahaan. Menentukan jenis penghubung yang akan digunakan, pilih sebuah koneksi dalam jaringan apakah menggunakan kabel atau juga menggunakan wireless ataupun kombinasi antara keduanya . setting alamat IP address sesuai dengan kelasnya masingmasing sehingga tiap-tiap komputer host bisa terkoneksi kedalam jaringan internet. Berikut macam-macam topologi jaringan komputer yang perlu diketahui

\section{Topologi Bus}

4 Topologi bus dirancang sedemikian rupa sehingga semua stasiun terhubung melalui okabel tunggal yang dikenal dengan sebagai kabel tulang punggung. Setiap node terhubung menggunakan kabel backbone dengan kabel drop atau terhubung langsung dengan kabel backbone.

Metode akses dari topologi jaringan bus yang paling umum adalah CSMA(Carrier Sense Multiple Access) ini merupakan sebuah kontrol yang mana akses media yang digunakan untuk mengontrol aliran data tersebut sehingga integritas dari sebuah data akan tetap terjaga yaitu paket tidak akan hilang. Ada dua cara alternatif untuk menangani masalah yang terjadi ketika dua node mengirim pesan secara bersamaan:

- CSMA CD adalah sebuah metode aksess yang digunakan untuk mendeteksi collison. Setelah tabrakan terdeteksi, pengirim akan berhenti mengirimkan data. Karena itu ia bekerja pada pemulihan setelah tabrakan.

- CSMA CA adalah sebuah metode akses yang digunakan untuk menghindari tabrakan dengan memeriksa apakah media transmisi sibuk atau tidak. Jika sibuk, makapengirim menunggu sampai media idle. Teknik ini secara efektif mengurangi kemungkinan tabrakan.

Karakteristik dari topologi Bus :

- Sederhana dalam hal instalasi.

- Dari segi biaya sangat ekonomis.

- ketika sebuah simpul ingin mengirimkan pesan melalui jaringan, ia mengirim pesan melalui jaringan. Semua stasiun yang tersedia di jaringan akan menerima pesan apakah sudah dialamatkan apa belum.

- Tidak memerlukan hub, karena yang banyak di gunakan adalah connector pada setiap Ethernet. 
- Permasalahan yang terjadi adalah ketika terjadi salah satu kerusakan dalam jaringan tersebut maka seluruhnya tidak bisa berkomunikasi.

\section{Kelebihan topologi Bus :}

- Tidak memerlukan kabel yang banyak dalam hal instalasinya.

- Lebih murah dibandingkan dengan topologi yang lainnya.

- Sangat simple dan sederhana.

- Ketika akan menambah jangkauan tidaklah rumit.

\section{Kekurangan topologi BUS :}

- Jika ada dua node mengirim pesan secara bersamaan, maka sinyal dari kedua node saling bertabrakan.

- Dibutuhkan peralatan uji khusus untuk menentukan kesalahan kabel. Jika ada kesalahan pada kabel, maka itu akan mengganggu komunikasi untuk semua node.

- Topologi bus sangat sederhana tetapi, masih membutuhkan banyak kabel.

- Menambahkan perangkat baru ke jaringan akan memperlambat jaringan.

- Atenuasi adalah hilangnya sinyal yang mengarah ke masalah komunikasi. Repeater digunakan untuk menguatkan sinyal.

\section{Topologi Star}

Seperti dengan namanya topologi ini memiliki sebuah penghubung yang di letakan ditengah yang di sambungkan dengan perangkat komputer yang lainnya. Alat penghubung tersebut adalah Hub/Switch.

\section{Karakteristik topologi Star:}

- Setiap komputer berkomunikasi langsung dengan HUB.

- Sangat mudah untuk dikembangkan.

- Jika ada satu komputer/kabel yang rusak maka tidak akan mempengaruhi jaringan yang lainnya.

- Kabel yang digunakan adalah kabel UTP.

\section{Kelebihan topologi Star:}

- Mudah dalam menambah ataupun mengubah komputer kedalam jaringan tanpa menggangu aktivitas jaringan yang lainnya.
- Kegagalan terbatas karena setiap stasiun yang terhubung ke hub sebagai pusatnya menggunakan kabelnya sendiri, maka kegagalan dari satu kabel tidak akan mengganggukeseluruhan dari jaringan.

- Dapat menggunakan beberapa jenis tipe kabel.

\section{Kelemahan topologi Star :}

- Jika hub sebagai penghubungnya gagal/error maka seluruh jaringan akan gagal untuk beroprasi.

- Boros dalam penggunaan kabel, karena satu komputer satu jalur kabel yang terhubung ke HUB.

- Jaringan bekerja lambat hal ini terjadi karena lalu lintas data yang padat.

\section{Topologi Ring}

Sesuai dengan namanya topologi ring berbentuk seperti cincin yang melingkar. Topologi ini di desain dimana setiap pusatnya dirancang agar bisa saling berinteraksi satu sama lain.

\section{Karakteristik topologi Ring:}

- Tampilannya sederhana seperti dengan topologi BUS.

- Kabel yang digunakan adalah jenis kabel UTP.

- Jika terdapat salah satu node yang bermasalah maka akan mengganggu jaringan yang lainnya.

\section{Kelebihan topologi Ring:}

- Mudah dibuat daan juga sederhana.

- Memiliki performa yang lebih tinggi dibandingkan dengan topologi Bus.

- Tidak memerlukan Hub, Switch dan bridge dalam membuat topologi Ring.

- Instalasi topologi ini sangat sederhana dan mudah sehngga dapat dilakukan oleh sendiri tanpa menjadi ahli IT.

\section{Kekurangan topologi Ring:}

- Butuh penangan dan maintenance khusus bandles.

- Jaringan topologi ini jarang digunakan karena kurang efisien. Konfigurasi jaringan lebih susah dibanding dengan konfigurasi jaringan topologi star. 
- Membutuhkan waktu yang lama dalam melakukan transfer data karena harus melewati masingmasing komputer yang dilewatinya.

\section{Topologi Mesh}

Topologi Mesh adalah pengaturan jaringan dimana komputer saling berhubungan antara satu sama lain melalui berbagai koneksi yang berlebihan.Topologi mesh terutama digunakan untuk implementasi WAN di mana kegagalan komunikasi merupakan masalah kritis. Internet merupakan contoh dari topologi mesh.

Topologi mesh dibedakan menjadi dua kategori :

- Topologi jala penuh, dalam topologi ini setiap komputer terhubung ke semua komputer yang tersedia di jaringan.

- Topologi mesh parsial, dalam topologi ini tidak semua kecuali komputer tertentu terhubung ke komputer yang sering digunakan untuk saling berkomunikasi.

\section{Kelebihan topologi mesh:}

- Mudah dalam hal mengidentifikasi masalah yang terjadi antar jaringan komputer.

- Security dan privacy dapat terjamin karena komunikasi yang terjalin diantara kedua komputer tersebut dapat diakses dengan komputer yang lainnya.

- Dapat menjamin jika data yang akan dikirimkan langsung ke komputer tujuan maka tanpa harus melewati komputer lainnya.

\section{Kekurangan topologi mesh:}

- Topologi mesh berisi sejumlah besar perangkat yang terhubung seperti router dan lebih banyak media transmisi daripada topologi jaringan yang lainnya sehingga memakan biaya yang besar.

- Manajemen, jaringan topologi mesh sangat besar dan sanga sulit untuk dipertahankan dan dikelola. Jika jaringan tidak di monitor dengan hati-hati maka kegagalan tautan komunikasi tidak terdeteksi.
- Dalam topologi mesh koneksi redundan tinggi yang mengurangi efisiensi jaringan.

\subsection{Jenis-Jenis Jaringan Komputer}

Dalam membentuk sebuah jaringan tentunya harus sesuai dengan kebutuhan yang diinginkannya karena ada beberapa jenis-jenis jaringan komputer yang memiliki tingkatan-tingkatan yang berbeda tentunya semakin besar tingkatannya maka semakin besar pula cakupan dari jaringan tersebut. Berikut ini beberapa jenis-jenis jaringan komputer yang perlu di ketahui:

\section{Local Area Network (LAN)}

Merupakan sekelompok komputer yang terhubung satu sama lain di area yang skalanya lebih kecil seperti gedung dan digunakan untuk menghubungkan tiap-tiap komputer dengan workstation dalam suatu jaringan di sebuah perusahaan untuk memakai sumber daya bersama-sama seperti contohnya penggunaan printer untuk mencetak sebuah dokumen dan juga untuk saling bertukar data informasi yang cakupannya masih dalam satu area.

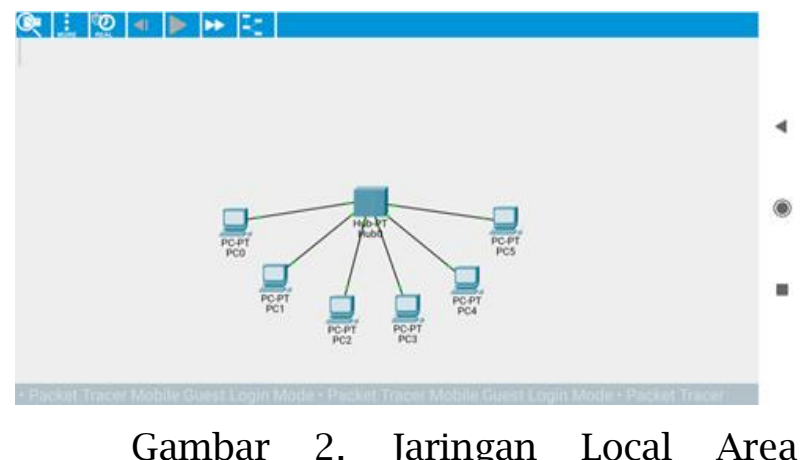
Network

Gambar 2. Jaringan Local Area

\section{Metropolitan Area Network}

Metropolitan area Network (MAN) merupkan sebuah jaringan yang jangkauannya lebih luas dibanding dengan jaringan Local Area Network, jaringan ini menghubungkan beberapa jaringan LAN kedalam lingkungan yang lebih besar, suatu jaringan MAN biasanya interkoneksi dengan sejumlah jaringan LAN menggunakan teknologi backbone berkapasitas tinggi, dalam MAN berbagai LAN terhubung melalui saluran pertukaran telepon. Protokol yang paling banyak digunakan dalam MAN adalah RS-232, frame Relay, ATM, ISDN, OC-3, ADSL. 


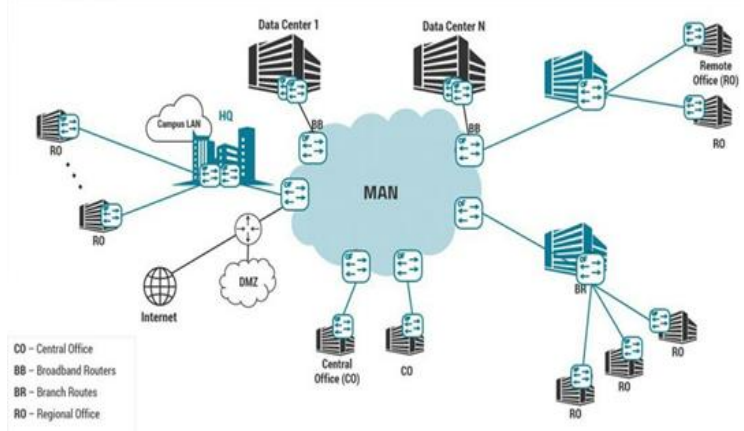

Gambar 3. Jaringan Metropolitan Area Network (MAN)

Penggunaan jaringan MAN:

- MAN digunakan dalam komunikasi antar bank disuatu kota.

- Dapat digunakan dalam reservasi pesawat.

- Dapat digunakan di perguruan tinggi.

- Dapat digunakan untuk keperluan militer dalam hal komunikasi.

\section{Wide Area Network (WAN)}

Merupakan jaringan yang didasarkan pada jangkauan geografis yang memiliki jangkauan yang sangat besar. WAN menghubungkan jenis jaringan yang lebih kecil seperti LAN dan MAN. Hal ini untuk memastikan komputer pengguna disuatu lokasi dapat berkomunikasi dengan pengguna yang lainnya di suatu lokasi yang berbeda. WAN bisa dijalankan dengan menggunakan bantuan sebuah transmisi publik atau jaringan pribadi. Dalam sebuah perusahaan, WAN dapat terdiri dari koneksi perusahaan pusat, kantor cabang, dan fasilitas perusahaan tersebut. Biasanya untuk mengkoneksikan LAN ke WAN menggunakan router atau perangkat multifungsi lainnya .

Koneksi jaringan WAN dapat berupa jaringan dengan berteknologi kabel(wired) atau nirkabel(wireless). Jenis jaringan WAN yang menggunakan kabel dapat terdiri dari multiprotocol label switching, Tis, Ethernet, dan koneksi broadband. Sedangkan untuk jenis jaringan WAN yang nirkabel atau tanpa kabel meliputi data seluler seperti 3G, $4 \mathrm{G}$ dan jaringan wi-Fi atau menggunakan jaringan satelit.

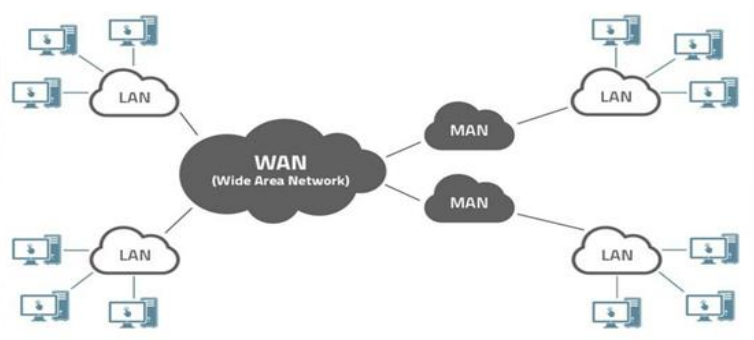

Gambar 4. Jaringan Wide Area Network (WAN)

Contoh jaringan WAN:

- Mobile broadbrand jaringan 4G yang banyak digunakan di suatu wilayah atau disuatu negara.

- Last mile, sebuah perusahaan telekomunikasi digunakan untuk menyediakan layanan internet kepada pelanggan di ratusan kota dengan menghubungkan rumah meraka dengan fiber.

- Jaringan pribadi, bank memiliki jaringan pribadi yang menghubungkan 44 kantor. Jaringan ini dibuat dengan menggunakan saluran telepon yang disediakan oleh perusahaan telekomunikasi.

\subsection{Internetwork}

Internetwork didefinisikan sebagai dua atau lebih LAN jaringan komputer atau WAN atau segmen jaringan komputer yang terhubung menggunakan sebuah perangkat, dan mereka dikonfigurasikan oleh skema pengalamatan lokal. Proses ini disebut dengan internetworking. Interkoneksi antara jaringan komputer untuk kepentingan publik, kepentingan swasta, kepentingan komersial, kepentingan sebuah industri, atau kepentingan sebuah pemerintahan juga dapat disebut sebagai internetworking. Internetworking menggunakan protokol internet. Model referensi yang digunakan untuk internetworking adalah Open System Interconnection(OSI).

\section{Jenis-jenis Internetwork:}

- Extranet : Extranet adalah sebuah sebuah jaringan komunikasi berdasarkan protokol internet seperti protokol kontra transmisi dan protokol internet. Akses ke extranet dibatasi hanya pengguna yang 
memiliki kredensial masuk. Extranet adalah internetworking terendah, ini dapat dikategorikan sebagai MAN, WAN atau jaringan komputer lainnya.

- Intranet : Intranet adalah jaringan pribadi berdasarkan protokol internet seperti seperti protokol kontrol transmisi dan protokol internet. Intranet milik organisasi yang hanya dapat diakses oleh karyawan atau anggota organisasi. Tujuan utama dari intranet adalah untuk berbagi sumber daya dan berbagai informasi diantara karyawan organisasinya.

\subsection{Komponen Jaringan Komputer}

Dalam membentuk sebuah jaringan komputer, tentunya dibutuhkan sebuah komponen komponen pendukungnya, sangat penting bagi kita mengetahuinya dan mengerti fungsi masing masing komponen tersebut sehingga nantinya tidak salah dalam menentukan komponen komponen yang dibutuhkan. Berikut ini beberapa komponen yang dibutuhkan bagi penulis untuk merancang sebuah simulasi jaringan komputer berbasis android menggunakan aplikasi Cisco Packet Tracer.

\section{HUB/SWITCH}

Hub adalah perangkat keras komputer yang digunakan sebagai penyambung atau concentrator dan untuk menguatkan sinyal jaringan pada kabel UTP, perangkat keras ini beroprasi pada lapisan OSI layer yang terendah yaitu Physical Layer.

Fungsi HUB dalam sebuah jaringan :

- Dapat menambah workstation.

- Dapat menambahkan jarak jaringan atau juga dapat difungsikan sebagai repeater.

- Support secara interface yang berbeda (Ethernet, Toket ring serta FDDI).

- Menerima sinyal dari satu komputer dan dapat mentransmisikan sinyal tersebut ke komputer lain.

- Sebagai media untuk membentuk sebuah topologi jaringan yaitu topologi star.

- Dapat memberikan management yang telah tersentralisasikan secara keseluruhan oleh jaringan tersebut.
Dapat memisahkan sebuah jaringan yang tidak memerlukan penggunaan listrik tambahan serta ada juga pemisah jaringan yang menguatkan sinyal dengan menggunakan listrik tambahan.

Switch adalah perangkat keras komputer yang digunakan sebagai penyambung atau sebagai concentrator dalam jaringan. Berbeda dengan HUB, switch tidak dapat mengalami collision karena switch dapat mengenali MAC address sehingga switch dapat memilah data yang akan di transmisikan.Switch beroprasi pada lapisan OSI yang ke dua yaitu Data Link Layer.

Fungsi switch dalam sebuah jaringan komputer.

komputer.

Menerima sinyal dan data dari

- Memperkuat sinyal transmisi dari server menuju client.

- Mengatur dan membatasi jumlah paket data ke client.

- Berfungsi juga sebagai repeater(penguat sinyal)

- Sebagai splitter atau pemisah.

\section{ROUTER}

Router adalah sebuah hardware yang digunakan sebagai penghubung antara sebuah jaringan yang akan meneruskan data dari jaringan yang satu ke jaringan yang lainnya. Router memiliki kemampuan yang jauh lebih banyak daripada perangkat lainnya,seperti hub atau switch yang mampu melakukan hal-hal dasar misalnya hub sering digunakan untuk mentransfer data antara komputer atau perangkat jaringan, tetapi tidak menganalisa atau melakukan apapun dengan data yang di transfer sebaliknya router dapat mengenali sebuah data yang di kirim melalui jaringan,mengubah cara pengemasan, dan mengirimkannya ke jaringan yang lain atau melalui jaringan yang lainnya. Misalnya router biasanya digunakan di jaringan rumah untuk berbagi koneksi internet tunggal dan dapat di sharring ke alamat IP address komputer yang lainnya. Berdasarkan mekanismenya router dibedakan menjadi 3 yaitu : 
1.Router Statis, yaitu sebuah router yang mampu untuk melakukan proses sebuah routing, yang dimaksud adalah bahwa suatu jaringan yang mana prosesnya dapat dilakukan secara manual oleh seorang administrator.

2.Router dinamis, yaitu sebuah router yang mampu melakukan proses routing, yang dimaksud di sini adalah bahwa setelah seorang administrator telah melakukan pengaturan pada router tersebut maka hal itu dapat berjalan secara dinamis dan otomatis.

3.Router wireless, yaitu router yang dapat bekerja tidak menggunakan kabel sebagai penghubungnya hal ini dikarenakan karena mengandalkan udara sebagai media untuk mengirimakan sebuah paket data.

\section{LAN CARD}

Lan card adalah perangkat keras komputer yang berfungsi sebagai media penghubung antara komputer dengan sebuah jaringan, Lan card dipasang pada motherboard pada slot PCI dan untuk menghubungkan jaringan komputer, pada umumnya Lan Card menggunakan port RJ45 dengan kabel yang digunakan adalah kabel UTP (Unshielded twisted pair).

\section{Kabel UTP (Unshielded Twisted Pair)}

Kabel adalah perangkat yang digunakan untuk pengantar arus yang terbuat dari tembaga yang dilapisi dengan karet sebagai lapisan luarnya. Sedangkan kabel UTP adalah jenis kabel yang digunakan dalam jaringan komputer yang menghubungkan dua buah komputer atau beberapa komputer didalam jaringan. Kabel UTP memiliki 2 jenis dalam hal pengkabelannya, yang pertama adalah pengkabelan jenis kabel straight yang digunakan untuk menghubungkan antara komputer dengaan hub/switch. Sedangkan jenis pengkabelan yang kedua adalah pengkabelan jenis crossover cable yang digunakan untuk menghubungkan antara komputer dengan komputer, switch dengan switch, atau router dengan router. Dalam kabel UTP terdapat 8 buah kebel-kabel kecil yang masing masing dibedakan oleh sebuah warna sehingga dapat memudahkan dalam proses memasang sebuah konektor dan warna-warna dalam kabel UTP tentu juga digunakan untuk membedakan pada saat pengkabelan apakah jenis kabel straight atau jenis kabel crossover keduanya sangat berbeda ketika 8 buah kabel UTP di hubungkan ke konektor, urutan pemasangannya dibedakan oleh warnawarna kabel UTP. Konektor yang digunakan untuk menghubungkan kabel UTP yaitu konektor RJ 45 dan untuk merekatkan antara konektor dengan kabel digunakan sebuah tang yaitu bernama tang cramping yang berfungsi agar konektor terhubung dengan erat dan tidak longgar sehingga pada saat digunakan tidak terjadi masalah. Sebelum digunakan kabel UTP yang sudah dihubungkan dengan konektor dibutuhkan sebuah alat penguji, alat tersebut adalah LAN TESTER dimana memiliki 2 buah port untuk memasukan konektor RJ 45, LAN TESTER juga memiliki lampu indikator yang dapat menyala ketika digunakan dan ketika menyala port yang satu dan port yang satunya lagi maka lampu indikatornya akan menyala secara bersama-sama.

\subsection{SUBNETING}

Subnetmask adalah angka yang mendefinisikan kisaran alamat IP yang tersedia dalam jaringan. Subnet mask tunggal membatasi jumlah IP yang valid untuk jaringan tertentu dari ip address yang berfungsi untuk menunjukan dijaringan mana komputer ataup device berada, sedangkan host ID digunakan untuk menunjuk server,router,workstation, dan host TCP/IP lainnya yang berada didalam jaringan tersebut.

Subnet mask menyembunyikan atau menutupi bagian jaringan dari alamat IP sistem dan hanya menyisakan bagian host sebagai pengidentifikasi mesin.Ia menggunakan format yang sama dengan alamat IPv4 empat bagian dari satu hingga tiga angka, dipisahkan oleh titik-titik. Perlu diingat meskipun dinotasikan sebagai notasi bertitik tetapi subnetmask bukanlah sebuah alamat IP address. Setiap bagian dari subnet mask dapat berisi angka dari 0 hingga 255, seperti halnya alamat IP. Misalnya subnet mask khas untuk alamat IP kelas C.

\section{Hasil Dan Pembahasan}

Dalam membuat sebuah jaringan komputer tentunya permasalahan yang terjadi adalah 
ketika diuji coba tetapi tidak adanya koneksi yang terjadi, untuk itu penulis merancang sebuah jaringan yang bisa menjadi gambaran bagi seorang administrator jaringan dalam hal mengetahui informasi seputar jaringan yang sedang digunakan.

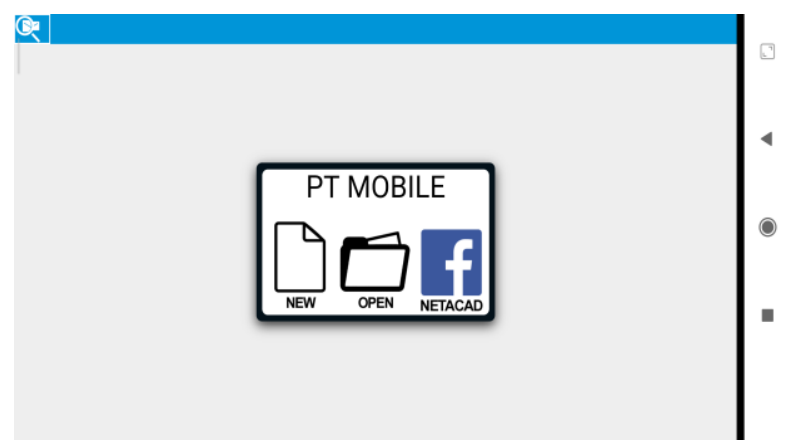

Gambar 5. Halaman kerja Cisco packet Tracer.

\subsection{Membuat Topologi Jaringan}

Untuk membuat sebuah topologi jaringan gunakan area lembar kerja pada aplikasi Cisco packet Tracer yang berbasis android dengan mengklik layar smartphone maka akan muncul beberapa pilihan seputar perangkat yang dibutuhan dalam membuat jaringan. Untuk itu pilih end device lalu akan muncul beberapa pilihan dalam hal ini pilihlah pc dan tentukan jumlah yang dibutuhkan setelah selesai maka pilihlah hub/switch dengan cara yang sama tekan layar smartphone pada halaman kerja Cisco packet Tracer. Hub /switch digunakan untuk membuat sebuah komputer/pc saling terhubung satu sama lain sehingga membentuk sebuah topologi jaringan. Untuk menghubungkan komputer/Pc dengan hub/switch, tekanlah gambar pc pada layar smartphone anda setelah itu akan muncul beberapa pilihan, pilihlah connect lalu pilih kabel straight, karena kabel straight digunakan untuk menghubungkan dua device yang berbeda. Setelah kabel dipilih maka tekan port pada komputer/pc yang tadi anda sudah pilih lalu hubungkan dengan port pada hub/switch dan nantinya akan muncul tanda titik hijau sebagai tanda bahwa komputer anda sudah terhubung dan membentuk sebuah topologi jaringan.

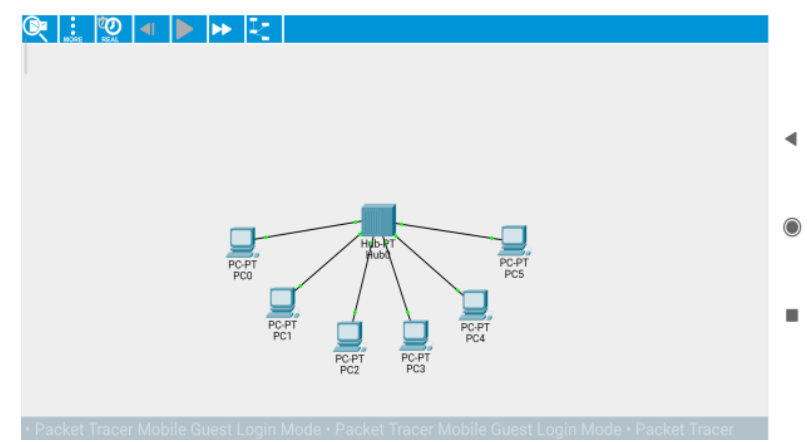

Gambar 6. Membuat Topologi Jaringan

\subsection{Menentukan Alamat IP address}

IP address merupakan sebuah identitas untuk perangkat keras komputer dalam jaringan. Untuk membuat IP address pada komputer anda pada aplikasi Cisco packet Tracer, maka tekan gambar komputer pada smartphone anda lalu akan muncul beberapa pilihan untuk itu pilihlah desktop lalu akan muncul lagi beberapa pilihan ,selanjutnya pilihlah IPv4 configuration lalu akan muncul untuk menyeting IP address, subnetmask, IP gateway yang akan di tentukan. Dalam suatu jaringan tentunya terdiri dari beberapa komputer bahkan jumlahnya bisa ratusan komputer yang terhubung dalam sebuah jaringan maka dalam mensetting komputer-komputer tersebut lakukan langkah langkahnya seperti yang tadi sudah dijelaskan hanya saja nomor IP addres yang terakhir tidak boleh sama dengan alamat IP address yang sudah digunakan, tentunya tetap dalam kelas IP yang sama seperti ditunjukan oleh gambar.

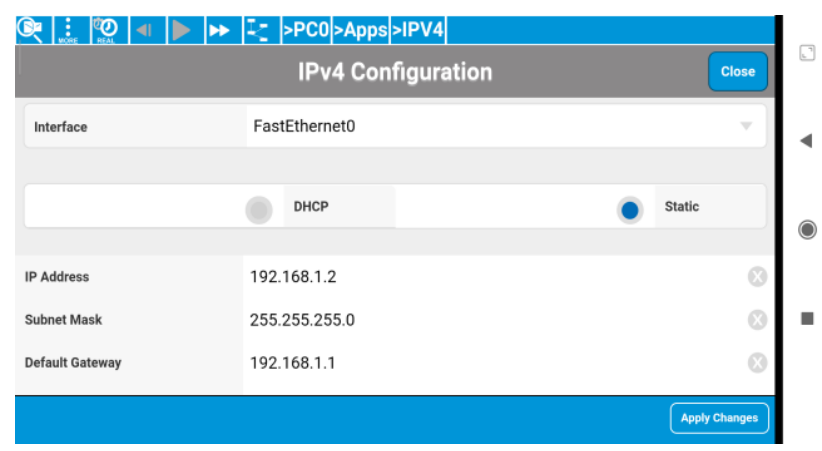

Gambar 7. Setting IP address. 


\subsection{Simulasi Jaringan Komputer}

Sebuah jaringan komputer pada dasarnya terdiri dari satu atau lebih komputer yang saling terhubung, sedangkan satu jaringan akan di hubungkan dengan jaringan yang lainnya dalam satu jaringan baik itu jaringan lokal maupun global. Hal ini dapat dilihat pada gambar 8 .

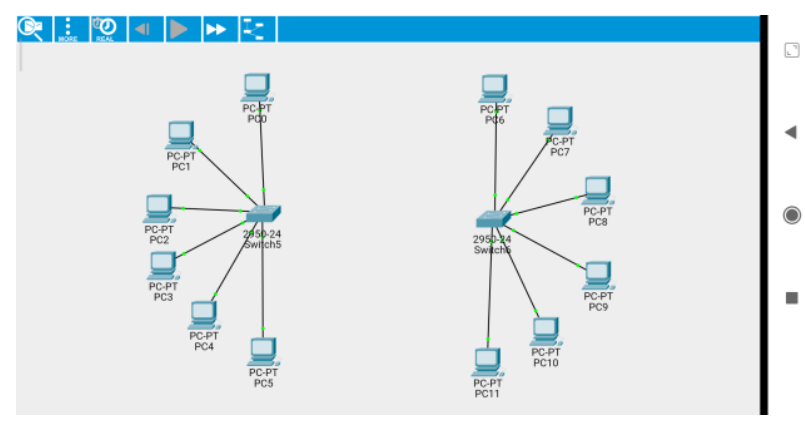

Gambar 8. simulasi dua buah jaringan

Pada sebuah simulasi jaringan komputer yang ditunjukan oleh gambar 8 terdapat dua buah jaringan komputer yang membentuk sebuah jaringan sendiri/terpisah, untuk menghubungkan satu jaringan dengan jaringan yang berbeda tersebut maka antara jaringan tersebut harus dihubungkan. Apabiala jaringan tersebut saat menggunakan alamat IP pada kelas yang sama maka bisa dengan menggunakan hub atau switch, tetapi apabila menggunakan kelas IP yang berbeda maka di butuhkan sebuah alat yang dapat mengontrol kedua jaringan tersebut yang yang akan dilalui yaitu dengan menggunakan router.

\subsection{Mensetting Router}

Agar kedua jaringan yang ditunjukan pada gambar bisa saling komunikasi satu sama lain dalam suatu jaringan, maka dibutuhkan sebuah alat yang bisa mengatur system pertukaran data yaitu dengan menggunakan router.

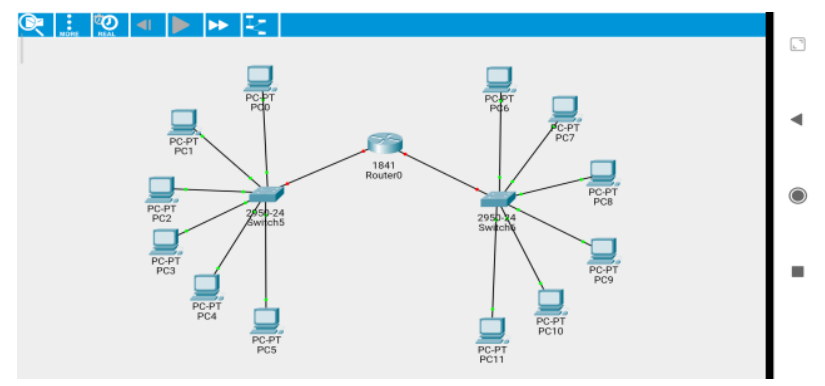

Gambar 9. Pemakaian Router
Untuk bisa menggunakan router maka router tersebut harus di setting agar masing- masing sebuah jaringan dapat terhubung satu sama lain, caranya yaitu klik gambar router pada layar smartphone anda lalu akan muncul beberapa pilihan untuk itu pilih printah config lalu akan muncul tampilan untuk mensetting router tersebut langkah selanjutnya ketik enable pada smartphone anda untuk memulai mensetting router selanjutnya ketik conf $t$ setelah itu ketik int fa0/0 hal ini bertujuan untuk mensetting port router yang pertama setelah selesai maka ketik IP gateway pada jaringan yang pertama ,IP gateway ini sebelumnya sudah di setting pada masingmasing komputer pada saat mensetting IP address jaringan yang pertama ataupun pada IP address komputer jaringan yang kedua, setelah ketik IP gateway ketikan juga subnetmask yang sebelumnya juga sudah di setting pada saat mensetting IP address, setelah selesai maka akan muncul teks berisikan pesan line protocol on interface fastethernet $0 / 0$, changed state to up , pesan ini bermaksud bahawa port router fa $0 / 0$ telah tersetting untuk terhubung dengan jaringan komputer yang pertama. Berhubung ada dua buah jaringan maka langkah selanjutnya dalam mensetting jaringan komputer yang kedua agar dapat terhubung dengan router maka ikuti langkah-langkahnya seperti pada saat mensetting router untuk jaringan yang pertama yang membedakan adalah ketika perintah int fa0/0 diganti dengan perintah int fa0/1 maksudnya adalah untuk mensetting port router yang kedua untuk digunakan pada jaringan yang kedua, dan juga ketika memasukan IP gateway pada perintah yang kedua ini maka pada perintah yang pertama IP gateway nya dirubah sesuai pada saat mensetting IP addrees untuk jaringan yang kedua, selanjutnya sampai akhir perintahnya sama dengan pada saat mensetting port router yang pertama. 


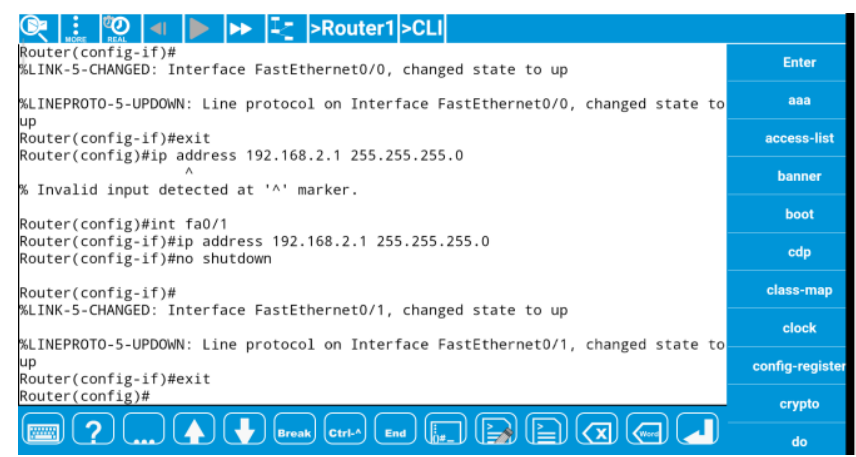

Gambar 10. Setting Router.

Setelah semua tahapan selesai maka jaringan komputer sudah terhubung dan masing masing jaringan komputer bisa saling berkomunikasi satu sama lain antar jaringan yang berbeda, jika pada saat mensetting tidak terdapat masalah maka gambar simulasi yang anda buat akan ditandai dengan indikasi titk-titik hijau pada pada komputer anda, tetapi ketika dalam mensetting terdapat masalah maka akan ditandai dengan titik-titik berwarna merah hal ini menandakan ada kesalahan pada saat melakukan setting pada router. Simulasi ini di tunjukan oleh gambar 11.

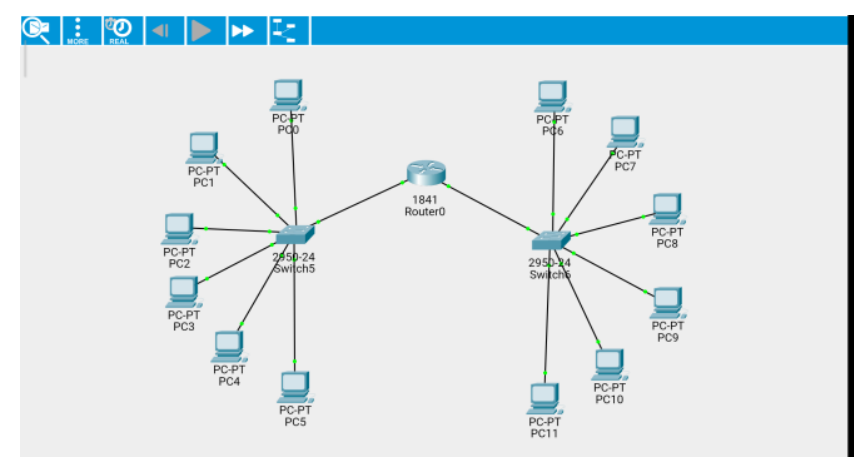

Gambar 11. Koneksi Router

\subsection{PENGUJIAN}

Setelah semua proses dari mulai membuat sebuah jaringan lalu mensetting IP address sampai setting pada router di lakukan, tentunya pengujian perlu dilakukan agar apa yang sudah dirancang dari awal dapat berjalan dengan baik tanpa ada kesalahan error yang terjadi. Untuk pengujian langkah pertama adalah tekan gambar komputer/pc pada simulasi jaringan yang sudah anda buat, setelah itu akan muncul beberapa pilihan, pilihlah desktop setelah itu pilihlah command

promt lalu ketikan sebuah printah yaitu ping dan ketikan alamat IP address yang akan diuji, jika tidak terjadi masalah maka akan muncul pesan balasan dari google seperti yang digambarkan oleh gambar 12 .

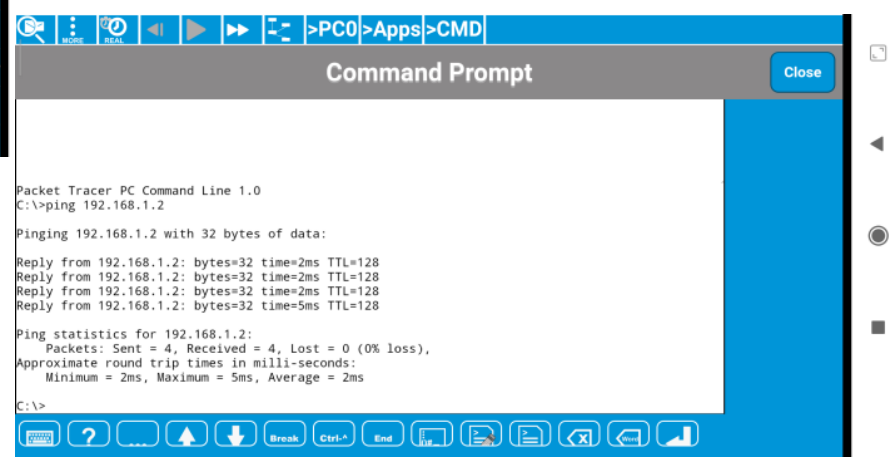

Gambar 12. Hasil konfigurasi pada IP address.

\section{Kesimpulan}

Setelah melakukan simulasi jaringan penulis melihat banyak sekali manfaat yang bisa diperoleh salah satunya adalah mengurangi resiko kesalahan pada saat merancang sebuah jaringan yang sesungguhnya. Lewat simulasi ini semua proses dari awal sampai akhir bisa kita liat hasilnya yaitu adanya koneksi antar komputer yang dirancang, tentunya hal ini sangat bermanfaat bagi seorang administrator jaringan sehingga nantinya resiko dari kesalahan dalam membuat sebuah jaringan dapat diminimalisir dan tentunya bisa menjadi sebuah gambaran mengenai jaringan komputer yang kita gunakan dalam kesehariannya.

\section{Daftar Pustaka}

Mufadhol, M. 2012. "Simulasi Jaringan Komputer Menggunakan Cisco Packet Tracer." Jurnal Transformatika 9(2): 64.

Ramadhan, Dian Saiful, and Naemah Mubarakah. 2013. "Perkantoran Dengan Menggunakan Software Cisco Packet Tracer." PERANCANGAN JARINGAN LAN PADA GEDUNG PERKANTORAN DENGAN MENGGUNAKAN SOFTWARE CISCO PACKET TRACER Dian 4(3): 100. 